Sely Novita Sari. 2019. Evaluasi Anggaran Biaya menggunakan Batu Bata Merah dan Batu Bata Ringan Gedung Kantor Kelurahan Bareng Kecamatan Klaten Tengah Kabupaten Klaten. Jurnal Qua Teknika, (2019), 9(1) : 1-10

\title{
EVALUASI ANGGARAN BIAYA MENGGUNAKAN BATU MERAH DAN BATU BATA RINGAN GEDUNG KANTOR KELURAHAN BARENG KECAMATAN KLATEN TENGAH KABUPATEN KLATEN
}

\author{
Sely Novita Sari \\ Program Studi Teknik Sipil Sekolah Tinggi Teknologi, Yogyakarta \\ Jalan Babarsari, Catur Tunggal, Depok, Sleman, Yogyakarta \\ Email : sely.novita@sttnas.ac.id
}

\begin{abstract}
ABSTRAK
Light brick is an alternative to making walls in addition to the red brick series used by ordinary people. The purpose of this study is to compare the calculation of budget costs and the need to use red brick walls with light brick walls. The implementation method is to calculate the unit price analysis of the installation of red brick and light brick, the AHS is multiplied by the volume and the RAB is obtained, then the calculated RAB is compared between the two. Conclusion the price of installing a red brick wall pair is Rp. 44,128,086.00. The price of installing a lightweight brick wall pair is Rp. 85,295,824.71. The difference between the two jobs is Rp. $41,167,738.71$. The percentage difference between the two jobs is $48.3 \%$.
\end{abstract}

Kata Kunci: Wall, Brick, Red, Light, Comparison

\section{PENDAHULUAN}

Pembangunan berkembang sangat pesat, pembangunan dari banyak aspek dilaksanakan di daerah akibat otonomi yang menghasilkan pembangunan sarana prasarana di tingkat daerah dilakukan dengan pesat. Pembangunan yang berkembang tersebut sudah masuk ke pembangunan gedung-gedung daerah untuk ditingkatkan fungsinya. Saat ini banyak pembangunan gedung kelurahan atau tingkat daerah dibangun ulang karena gedung yang lama sudah tidak bisa menampung kebutuhan isi di dalamnya, pembangunan diperlukan desain struktur dan biaya optimum sehingga harus mengestimasi biaya pembangunan gedung baru. Salah satu faktor yang mempengaruhi biaya konstruksi adalah material yang akan digunakan. Pelaksanaan pembangunan gedung terutama gedung tingkat tinggi sudah sangat popular dengan menggunakan bata ringan sebagai pengganti bata merah untuk pekerjaan pemasangan dinding karena memiliki kebutuhan material yang lebih sedikit permeter luasannya. Bata ringan memiliki kekurangan yaitu harganya lebih tinggi dibandingkan dengan harga bata merah, sehingga penggunaan bata ringan masih didominasi pada pekerjaan gedung bertingkat tinggi. Latar belakang diatas yang membuat terjadinya penelitian ini, bagaimana penerapan bata ringan pada gedung pemerintahan daerah dilaksanakan dari segi Anggaran Biayanya, sehingga didapat tujuan dari penelitian ini adalah mengetahui prosentase perbandingan anggaran biaya pekerjaan pasangan dinding bata merah dan dinding bata ringan.

Rancangan anggaran biaya adalah perhitungan biaya yang digunakan untuk penggunaan bahan dan upah tenaga kerja, serta biaya lainnya yang berhubungan dengan pelaksanaan bangunan tersebut (Ibrahim, 1993). Tahapan-tahapan yang dilakukan untuk menyusun anggaran biaya dapat dilihat dari langkah-langkah berikut yaitu [1] mencari data primer berupa jenis pengerjaan bangunan, harga sekitaran yang berlaku, seta mencari pemasok atau kemampuan pasar dalam menyediakan material konstruksi secara terus menerus. [2] mencari data primer tentang upah harian tenaga kerja yang berlaku di daerah sekitaran lokasi daerah proyek, biasanya data upah tenaga kerja menggunakan data pekerja harian pemerintah daerah setempat untuk penyamarataan harga, tetapi bisa juga menggunakan data upah harian tenaga menggunakan data keseharian pekerja lokasi proyek. [3] Melakukan perhitungan analisis bahan dan upah dengan menggunakan analisis yang sudah distandarkan untuk tujuan pemerataan perhitungan anggaran. Dipasaran terdapat buku BOW (Burgerlijke Openbare Werken) dan pemerintah menyiapkan SNI untuk menghitung Analisa Harga Satuannya. [4] Melakukan perhitungan harga satuan pekerjaan dengan menggunakan hasil analisis harga satuan pekerjaan dan daftar kuantitas pekerjaan. [5] Membuat Rekapitulasi dari seluruh kegiatan pelaksanaan proyek sehingga didapat rancangan anggaran biaya proyek yang diinginkan (Ervianto,2007)

Manajemen biaya proyek adalah proses yang diperlukan untuk memastikan dan memantau proyek akan diselesaikan sesuai dengan rancagan anggaran biaya yang telah disepakati. Biaya proyek atau anggaran proyek biasanya sangat terbatas sehingga diperlukan pengelolaan yang baik agar pengeluaran biaya proyek optimal. Pengelolaan biaya proyek disebut manajemen biaya proyek yang digunakan untuk menyelesaikan kegiatan dalam jadwal proyek agar tidak melampaui waku yang sudah ditetapkan. Manajemen biaya proyek meliputi 
Jurnal Qua Teknika, Vol. 9 No. 1 Maret 2019

ISSN 2088-2424 (cetak); ISSN 2527-3892 (elektronik)

Fakultas Teknik Universitas Islam Balitar, Blitar

Https://ejournal.unisbablitar.ac.id/index.php/qua; Email: quateknika@unisbablitar.ac.id

Sely Novita Sari. 2019. Evaluasi Anggaran Biaya menggunakan Batu Bata Merah dan Batu Bata Ringan Gedung Kantor Kelurahan Bareng Kecamatan Klaten Tengah Kabupaten Klaten.

Jurnal Qua Teknika, (2019), 9(1) : 1-10

proses-proses yang diperlukan untuk menjamin anggaran biaya yang telah dissepakati cukup untuk menyelesaikan semua pekerjaan dalam lingkup proyek. Saat pelaksanaan proyek selalu ada pekerjaan yang diluar perhitungan maka manajemen biaya proyek juga harus mempersiapkan beberapa langkah alternatif untuk menyelesaikan permasalahan lapangan diluar perencanaan. Proses-proses manajemen proyek yaitu:

1. Perencanaan sumber daya

2. Estimasi biaya (cost estimating)

3. Penganggaran biaya (cost budgeting)

4. Pengendalian biaya (cost control)

Biaya adalah semua pengorbanan yang perlu dilakukan untuk suatu proses menghasilkan barang atau produk untuk mencapai tujuan spesifik atau untuk mendapatkan sesuatu sebagai gantinya yang dinyatakan dengan uang menuru harga yang berlaku. Biaya proyek adalah biaya yang digunakan selama proyek itu dilaksanakan sampai proyek tersebut selesai pelaksanaannya. Berdasarkan pengertiannya,biaya terdiri dari biaya langsung (direct) dan biaya tidak langsung (indirect).

Biaya langsung (direct) adalah biaya yang terkait secara langsung dengan suatu proyek atau pekerjaan sehingga dapat ditelusuri secara tepat pembiayaannya. Contoh dari biaya langsung yaitu, upah tenaga kerja, pembelian bahan kebutuhan proyek, dll. Biaya tidak langsung (indirect) adalah biaya yang berhubungan dengan pelaksanaan proyek, tetapi tidak dapat ditelusuri secara tepat pembiayaannya. Contoh biaya tak langsung yaitu tagihan telepon perusahaan, biaya sewa bangunan kantor untuk kegiatan proyek.

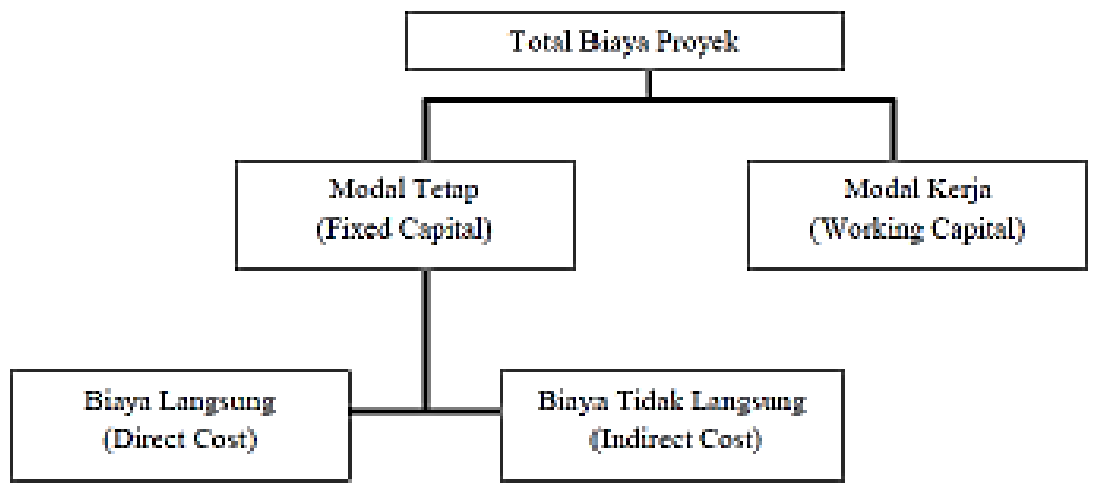

Gambar 1. Klasifikasi Perkiraan Biaya Proyek (Imam Soeharto, 1995)

Anggaran biaya adalah harga dari bangunan yang dianalisis biayanya dengan cermat, teliti dan memenuhi syarat yang disepakati. Anggaran biaya pada bentuk bangunan yang sama akan berbeda disetiap masing-masing daerah, perbedaan tersebut disebabkan oleh harga satuan upah dan harga bahan disetiap daerah tidak sama. Biaya (anggaran) adalah jumlah dari hasil perhitungan volume pekerjaan yang dilakukan dengan harga satuan pekerjaan yang bersangkutan.

Secara umum dapat disimpulkan sesuai rumus berikut

$$
\text { RAB }=\Sigma(\text { Volume }) \quad x \text { Harga Satuan Pekerjaan }
$$

Hal-hal yang perlu dipersiapan dalam penyusunan rencana anggaran biaya adalah sebagai berikut :

Persiapan Membuat Anggaran biaya

a. Tersedianya Gambar Rencana (Lengkap Termasuk Detail)

Gambar yang lengkap, jelas dan rinci sangat diperlukan untuk memudahkan perhitungan volume pekerjaan. Perhitungan volume pekerjaan dilakukan dengan cara menghitung seluruh volume pelaksanaan pekerjaan berdasarkan gambar kerja yang telah dissepakati, kemudian dirincinkan secara khusus sesuai dengan pekerjaan pelaksanaan yang akan dihitung. Gambar rencana ini sedikitnya harus meliputi gambar denah, potongan, tampak (depan, samping kanan, samping kiri, dan belakang), struktur rencana atap, serta gambar detailnya.

b. Rencana Kerja dan Syarat-Syarat (RKS)

RKS berfungsi dalam menentukan spesifikasi material bahan, kualitas dan metode pelaksanaannya. Secara umum RKS meliputi aspek teknis dan administratif yang terdiri dari jenis bahan, kualitas, standar pekerjaan maupun bahan, jaminan aturan pembayaran dan lainya.

c. Survei Bahan dan Material, survei ini berguna untuk : 
Jurnal Qua Teknika, Vol. 9 No. 1 Maret 2019

ISSN 2088-2424 (cetak); ISSN 2527-3892 (elektronik)

Fakultas Teknik Universitas Islam Balitar, Blitar

Https://ejournal.unisbablitar.ac.id/index.php/qua; Email: quateknika@unisbablitar.ac.id

Sely Novita Sari. 2019. Evaluasi Anggaran Biaya menggunakan Batu Bata Merah dan Batu Bata Ringan Gedung Kantor Kelurahan Bareng Kecamatan Klaten Tengah Kabupaten Klaten.

Jurnal Qua Teknika, (2019), 9(1) : 1-10

1. Mengetahui harga dipasaran sekitaran proyek.

2. Mengetahui perubahan harga dan ketersedianya bahan dipasaran (kemampuan pasar menyediakan bahan material)

3. Mengetahui kebutuhan material maupun alat yang diperlukan untuk pelaksanaan proyek.

4. Bahan-bahan khusus yang tidak bisa langsung ada dipasaran sekitar, termasuk bila harus dipesan terlebih dahulu (special order).

d. Survei Upah Tenaga kerja, meliputi :

1. Upah mandor, tukang dan tenaga.

2. Upah jasa borong dan juga mengetahui harga satuan material

3. Produktifitas dari para tenaga kerja.

e. Survei Kondisi Lapangan

Survei kondisi lapangan merupakan survei terhadap kondisi dan letak proyek, karena ini akan terkait dengan persediaan bahan dan material, kondisi jalan menuju proyek untuk pengangkutan bahan, termasuk juga yang berkaitan dengan ketersediaannya air disekitar lingkungan proyek. Selain itu berkaitan dengan aspek ekonomi sosial dan budaya pada daerah tersebut

f. Data-data lain yang secara khusus diperlukan baik secara teknis maupun nonteknis.

Pembuatan Rencana Anggaran Biaya (RAB). Data yang diperlukan dalam pelaksanaan pembuatan rencana anggaran biaya $(\mathrm{RAB})$ adalah sebagai berikut:

1. Daftar analisis, baik analisis SNI yang berlaku maupun BOW hasil perhitungan lapangan, daftar analisis ini biasanya konsultan dan kontraktor memiliki acauan tersendiri ata menyesuaikan dengan acuan yang ada dipemerintahan.

2. Volume pekerjaan yang diperhitungkan secara keseluruhan

3. Tingkat kesulitan pekerjaan juga harus dipahami dan diperhitungkan secara teknis dan non teknis seperti dari segi waktu pelaksanaan, artinya bila pekerjaan tersebut memerlukan keahlian tersendiri atau membutuhkan waktu pekerjaan yang lebih cepat atau lama dalam kondisi proyek kritis.

Analisa harga satuan pekerjaan merupakan perhitungan analisa bahan, upah tenaga kerja, dan peralatan untuk membuat satu-satuan pekerjaan tertentu yang diatur standar yang ditetapkan, dari hasilnya didapatkan koefisien untuk mengalikan bahan, upah tenaga kerja, dan peralatan segala jenis pekerjaan proyek. Harga satuan pekerjaan terdiri dari tiga komponen, yaitu:

a. Analisa harga satuan bahan/ matrial

Menghitung volume masing-masing bahan yang digunakan, serta besarnya biaya yang dibutuhkan dalam pelaksanaan. Kebutuhan bahan dan material ialah besarnya jumlah bahan dan material yang dibutuhkan untuk menyelesaikan sebuah pekerjaan. (Ibrahim, 1993)

Kebutuhan bahan dapat dicari dengan rumus berikut

\section{$\Sigma$ Bahan $=$ Volume pekerjaan $x$ Koefisien analisa bahan}

Koefisien analisa bahan merupakan koefisien kuantum yang memperlihatkan kebutuhan bahan bangunan untuk setiap satuan jenis pekerjaan. Analisa bahan dari suatu pekerjaan merupakan kegiatan menghitung volume masing-masing bahan yang dibutuhkan, serta menunjukan kebutuhan bahan yang diperlukan untuk menghasilkan volume kebutuhan pekerjaan tersendiri yang akan dikerjakan .

1. Analisa harga satuan upah tenaga

Menghitung banyaknya tenaga yang digunakan, serta besarnya biaya yang dibutuhkan untuk melakukan pekerjaan tersebut. Kebutuhan tenaga kerja ialah besarnya jumlah tenaga kerja yang digunakan untuk menyelesaikan pekerjaan tergantung dari kualitas dan kuantitas pekerjaannya (Ibrahim, 1993). Secara umum jumlah tenaga kerja yang dibutuhkan untuk suatu volume pekerjaan tertentu dapat dicari dengan rumus berikut.

\section{$\Sigma$ Tenaga Kerja $=$ Volume pekerjaan $\mathbf{x}$ Koefisien analisa tenaga}

2. Analisa harga satuan alat

Analisa harga satuan alat adalah menghitung kebutuhan alat yang diperlukan serta besarnya biaya persewaan alat, untuk dapat menyelesaikan pekerjaan konstruksi. Volume pekerjaan adalah menghitung banyaknya pekerjaan dalam satu satuan luasan atau volume. Volume juga disebut 
Jurnal Qua Teknika, Vol. 9 No. 1 Maret 2019

ISSN 2088-2424 (cetak); ISSN 2527-3892 (elektronik)

Fakultas Teknik Universitas Islam Balitar, Blitar

Https://ejournal.unisbablitar.ac.id/index.php/qua; Email: quateknika@unisbablitar.ac.id

Sely Novita Sari. 2019. Evaluasi Anggaran Biaya menggunakan Batu Bata Merah dan Batu Bata Ringan Gedung Kantor Kelurahan Bareng Kecamatan Klaten Tengah Kabupaten Klaten.

Jurnal Qua Teknika, (2019), 9(1) : 1-10

sebagai kubikasi pekerjaan, jadi volume (kubikasi) suatu pekerjaan, bukanlah merupakan volume (isi sesungguhnya), melainkan jumlah volume bagian pekerjaan dalam satu kesatuan (Ibrahim, 1993). Menghitung volume masing-masing pekerjaan terlebih dahulu dengan menguasai gambar bestek berikut gambar detail/penjelasan secara terinci. Gambar mulai dari denah sampai rencana sanitasi, masing-masing gambar dilengkapi dengan simulasi dan gambar isometrik untuk memudahkan menghitung bagian penting yang tidak terlihat pada gambar bestek.

Harga satuan pekerjaan adalah jumlah harga bahan dan upah tenaga kerja berdasarkan perhitungan analisis pekerjaannya. Harga bahan didapat di pasaran sekitar lokasi, dikumpulkan dalam satu daftar yang dinamakan daftar harga satuan bahan. Upah tenaga kerja didapatkan dilokasi atau menggunakan daftar tenaga kerja dari pemerintah sekitar dikumpulkan dan di catat dalam satu daftar dinamakan daftar harga satuan upah. Harga satuan bahan dan upah tenaga kerja di setiap daerah berbeda-beda tergantung dengan kebutuhan daerahnya. Jadi dalam menghitung dan menyusun anggaran biaya suatu proyek, harus berpedoman pada harga satuan bahan dan upah tenaga kerja di pasaran dan lokasi pekerjaaan. (Ibrahim, 1993)

Daftar harga satuan bahan berisi daftar bahan-bahan bangunan yang akan digunakan untuk pelaksanaan pekerjaan sebuah proyek. Satuan dari bahan-bahan bangunan tersebut tergantung dari jenis dan macam bahanbahan bangunan yang dibutuhkan. Daftar harga satuan upah tenaga berisi upah orang harian dari tenaga kerja yang akan digunakan sebagai tenaga pelaksana lapangan. Tenaga kerja yang biasa digunakan untuk sebuah proyek, yaitu pekerja, tukang, kepala tukang, mandor, dan sebagainya. (Djojowirono, 1991)

Upah tenaga kerja didapatkan dilokasi, dikumpukan dan dicatat dalam satu daftar yang dinamakan Daftar Harga Satuan Upah. Untuk menentukan upah tenaga kerja dapat diambil standar harga yang berlaku di pasaran atau daerah tempat proyek dikerjakan yang sesuai dengan spesifikasi dari dinas Pekerjaan Umum (PU). Untuk meentukan harga bangunan dapat diambil standar harga yang berlaku di pasar atau daerah tempat proyek dikerjakan sesuai dengan spesifikasi dari dinas Pekerjaan Umum (PU) setempat yang dinamakan Daftar Harga Satuan Bahan. Pada analisa ini sudah termasuk perlatan kerja atau setiap pekerja harus mempunyai peralatan kerja sendiri yang mendukung keahlian masing-masing. Untuk menentukan harga satuan alat dapat diambil standar harga yang berlaku di pasar atau daerah tempat proyek dikerjakan sesuai dengan spesifikasi dari dinas Pekerjaan Umum setempat yang dinamakan Daftar Harga Satuan Alat. Secara umum dapat disimpulkan rumus berikut.

\section{Harga Satuan Pekerjaan = H. S. Bahan + H. S. Upah + H. S. Alat}

Tabel 1. Analisa Harga Satuan pasangan dinding bata merah menurut SNI 2016 A.4.4.1.9 Pemasangan $1 \mathrm{~m}^{2}$ dinding bata merah $(5 \times 11 \times 22) \mathrm{cm}$ tebal $1 / 2$ batu campuran $1 \mathrm{SP}: 4 \mathrm{PP}$

\begin{tabular}{|c|c|c|c|c|c|c|}
\hline No & Uraian & Kode & Satuan & Koefisien & $\begin{array}{c}\text { Harga } \\
\text { Satuan } \\
\text { (Rp) }\end{array}$ & $\begin{array}{c}\text { Jumlah } \\
\text { Harga } \\
\text { (Rp) }\end{array}$ \\
\hline \multirow[t]{6}{*}{$\mathrm{A}$} & TENAGA & & & & & \\
\hline & Pekerja & L.01 & $\mathrm{OH}$ & 0,300 & & \\
\hline & Tukang batu & L.02 & $\mathrm{OH}$ & 0,100 & & \\
\hline & Kepala tukang & L.03 & $\mathrm{OH}$ & 0,010 & & \\
\hline & Mandor & L.04 & $\mathrm{OH}$ & 0,015 & & \\
\hline & & & & JUMLAH TE & GA KERJA & \\
\hline \multirow[t]{5}{*}{$\mathrm{B}$} & BAHAN & & & & & \\
\hline & Bata merah & & buah & 70,000 & & \\
\hline & Semen Portland & & $\mathrm{Kg}$ & 11,500 & & \\
\hline & Pasir pasang & & $\mathrm{m}^{3}$ & 0,043 & & \\
\hline & & & & JUMLAH HA & BAHAN & \\
\hline \multirow[t]{4}{*}{ c } & PERALATAN & & & & & \\
\hline & & & & & & \\
\hline & & & & JUMLAH HA & A ALAT & \\
\hline & & & & & & \\
\hline D & \multicolumn{5}{|l|}{ Jumlah $(A+B+C)$} & \\
\hline E & \multirow{2}{*}{\multicolumn{3}{|c|}{$\begin{array}{l}\text { Overhead \& Profit /Contoh 15\%) } \\
\text { Harga Satuan Pekerjaan (D+E) }\end{array}$}} & \multirow{2}{*}{\multicolumn{2}{|c|}{$15 \% \times \mathrm{D}$ (makssimum) }} & \\
\hline F & & & & & & \\
\hline
\end{tabular}


Jurnal Qua Teknika, Vol. 9 No. 1 Maret 2019

ISSN 2088-2424 (cetak); ISSN 2527-3892 (elektronik)

Fakultas Teknik Universitas Islam Balitar, Blitar

Https://ejournal.unisbablitar.ac.id/index.php/qua; Email: quateknika@unisbablitar.ac.id

Sely Novita Sari. 2019. Evaluasi Anggaran Biaya menggunakan Batu Bata Merah dan Batu Bata Ringan Gedung Kantor Kelurahan Bareng Kecamatan Klaten Tengah Kabupaten Klaten.

Jurnal Qua Teknika, (2019), 9(1) : 1-10

Tabel 2. Analisa Harga Satuan pasangan dinding bata ringan menurut SNI 2016

A. 4.4.1.25 Pemasangan $1 \mathrm{~m}^{2}$ dinding bata ringan tebal $7,5 \mathrm{~cm}$ dengan mortar siap pakai

\begin{tabular}{|c|c|c|c|c|c|c|}
\hline No & Uraian & Kode & Satuan & Koefisien & $\begin{array}{c}\text { Harga } \\
\text { Satuan } \\
\text { (Rp) }\end{array}$ & $\begin{array}{c}\text { Jumlah } \\
\text { Harga } \\
\text { (Rp) }\end{array}$ \\
\hline \multirow[t]{6}{*}{ A } & TENAGA & & & & & \\
\hline & Pekerja & L.01 & $\mathrm{OH}$ & 0.67 & & \\
\hline & Tukang batu & L.02 & $\mathrm{OH}$ & 1.300 & & \\
\hline & Kepala tukang & L. 03 & $\mathrm{OH}$ & 0.13 & & \\
\hline & Mandor & L.04 & $\mathrm{OH}$ & 0.003 & & \\
\hline & & & & \multicolumn{2}{|c|}{ JUMLAH TENAGA KERJA } & \\
\hline \multirow[t]{4}{*}{ B } & BAHAN & & & & & \\
\hline & $\begin{array}{l}\text { Bata ringan tebal } \\
7,5 \mathrm{~cm}\end{array}$ & & $\mathrm{~m}^{3}$ & 8.40 & & \\
\hline & Mortar siap pakai & & $\mathrm{Kg}$ & 0.473 & & \\
\hline & & & & \multicolumn{2}{|c|}{ JUMLAH HARGA BAHAN } & \\
\hline \multirow[t]{4}{*}{ C } & PERALATAN & & & & & \\
\hline & Peralatan & & $\%$ & 10 & & \\
\hline & & & & \multicolumn{2}{|c|}{ JUMLAH HARGA ALAT } & \\
\hline & & & & & & \\
\hline $\mathrm{D}$ & \multicolumn{5}{|l|}{ Jumlah $(A+B+C)$} & \\
\hline$E$ & \multicolumn{3}{|c|}{ Overhead \& Profit (Contoh $15 \%$ ) } & \multirow{2}{*}{\multicolumn{2}{|c|}{$15 \%$ x D (maksimum) }} & \\
\hline F & Harga Satuan Pekeri. & $\operatorname{aan}(D+1)$ & & & & \\
\hline
\end{tabular}

Dinding adalah suatu struktur padat yang membatasi dan kadang melindungi suatu area. Umumnya, dinding membatasi suatu bangunan dan menyokong struktur lainnya, membatasi ruang dalam bangunan menjadi ruanganruangan, atau melindungi atau membatasi suatu ruang di alam terbuka. Tiga jenis utama dinding struktural adalah dinding bangunan, dinding pembatas (boundary), serta dinding penahan (retaining). Dinding bangunan memiliki dua fungsi utama, yaitu menyokong atap dan langit-langit, membagi ruangan, serta melindungi terhadap intrusi dan cuaca. Bata merah adalah suatu unsur arsitektural mendukung konstruksi inti bangunan yang terbuat dari tanah dan campuran bahan-bahan lain yang dibakar dengan suhu tinggi, hingga tidak bisa hancur bila direndam oleh air. Bata ringan adalah campuran pasir kwarsa, semen, kapur, sedikit gypsum, air, dan aluminium pasta sebagai bahan pengembang (pengisi udara secara kimiawi) dilakukan campuran dengan kimiawi sehingga menghasilkan beton yang ringan akibat rongga-rongga udara yang ada. Bata ini cukup ringan, halus, dan memiliki tingkat kerataan yang baik sehingga bisa langsung diberi aci tanpa harus diplester terlebih dahulu. Bahan untuk acian biasanya menggunakan semen instan atau semen khusus. Semen ini berbahan dasar pasir silika, semen, filler, dan zat aditif. Penggunaanya hanya dicampur dengan air, tetapi dapat juga menggunakan bahan seperti pemasangan batako. Bata Celcon memiliki ukuran $60 \mathrm{~cm} 20 \mathrm{~cm}$ dengan ketebalan $8-10 \mathrm{~cm}$.

\title{
METODE PENELITIAN
}

Penelitian ini untuk mengetahui prosentase perbedaan rancangan anggaran biaya pemasangan dinding menggunakan bata merah dan bata ringan. Data sekunder yang didapatkan adalah berupa gambar asbuild drawing dan shop drawing, daftar harga satuan bahan 2017, daftar harga satuan upah 2017, SNI No. 28/PRT/2016 tentang analisa harga satuan tahun 2016, rencana anggaran biaya penawaran. Data primer yang dibutuhkan adalah volume pasangan dinding didapat dari gambar asbuild drawing dan shop drawing, analisa harga satuan didapat dari SNI No. 28/PRT/2016 tentang analisa harga satuan tahun 2016, Rancangan anggaran biaya pasangan dinding didapat dari perkalian volume dan analisa harga satuannya. Rancangan angaran biaya yang terhitung untuk bata merah dan bata ringan dibandigkan dan dibuat prosentase perbandingan, mana yang lebih mahal dan murah dari segi biayanya.

Subjek pada penelitian ini adalah atap pada bangunan gedung kelurahan Bareng, kecamatan Klaten Tengah, kabupaten Klaten. Untuk data yang lebih lengkap dapat dilihat sebagai berikut:
1. Pembangunan
2. Lokasi
3. Pemilik Proyek
4. Kontraktor Pelaksana
5. Konsultan Perencana

\author{
: Kantor Kelurahan Bareng \\ : Kelurahan Bareng, Kecamatan Klaten Tengah, Kabupaten Klaten \\ : Pemerintah Kabupaten Klaten \\ : CV. Budi Karya Utama \\ : CV. Sakalike
}


Jurnal Qua Teknika, Vol. 9 No. 1 Maret 2019

ISSN 2088-2424 (cetak); ISSN 2527-3892 (elektronik)

Fakultas Teknik Universitas Islam Balitar, Blitar

Https://ejournal.unisbablitar.ac.id/index.php/qua; Email: quateknika@unisbablitar.ac.id

Sely Novita Sari. 2019. Evaluasi Anggaran Biaya menggunakan Batu Bata Merah dan Batu Bata Ringan Gedung Kantor Kelurahan Bareng Kecamatan Klaten Tengah Kabupaten Klaten. Jurnal Qua Teknika, (2019), 9(1) : 1-10

6. Jenis Kontrak

: Unit price.

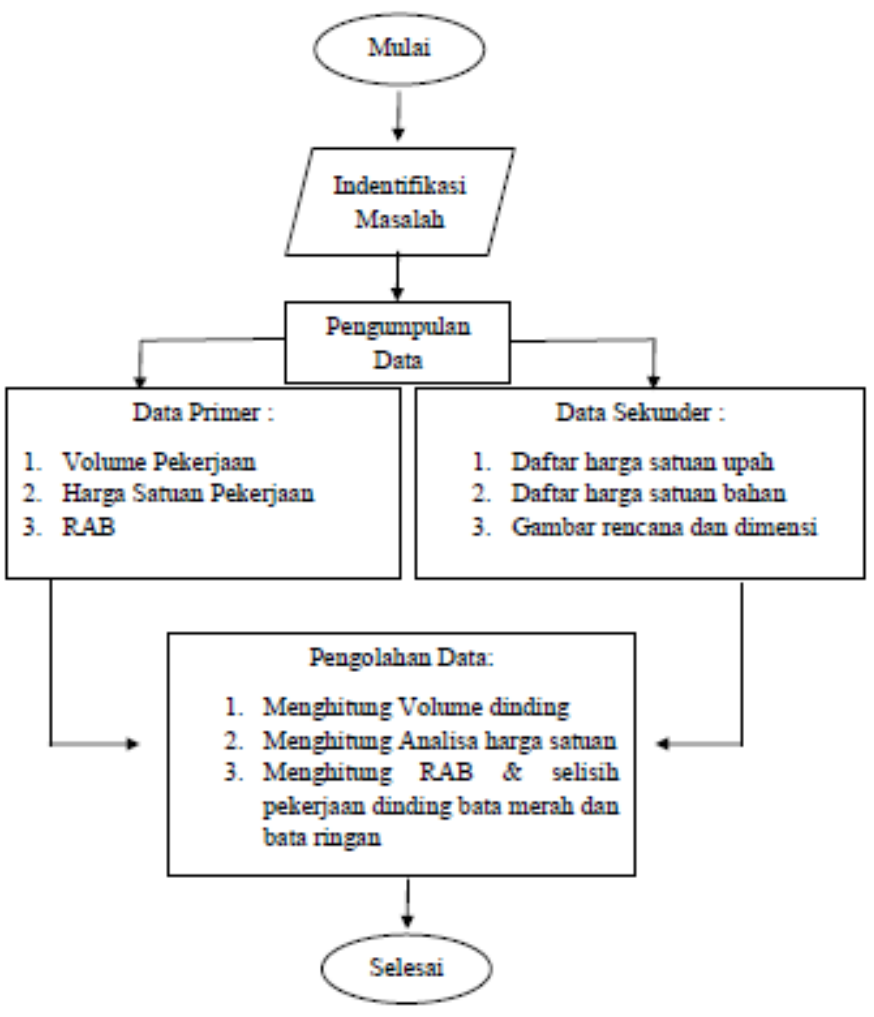

Gambar 2. Flow Chart Penelitian

Objek pada penelitian ini adalah menganalisa perbandingan hasil perhitungan anggaran biaya pada pekerjaan dinding antara menggunakan bata merah dengan bata ringan. Data-data yang diperlukan dalam penelitian ini terbagi menjadi dua yaitu data primer dan data sekunder. Data sekunder adalah data yang didapatkan dari sumber yang sudah ada, khusus untuk penelitian ini didapatkan dari pihak kontraktor. Data primer adalah data yang didapatkan secara langsung baik langsung melakukan penelitian atau langsung ke lapangan.

Data Sekunder yang didapatkan adalah:

1. Gambar Shop Drawing dan Asbuilt Drawing

2. Daftar harga satuan bahan yang digunakan di daerah penelitian.

3. Daftar harga satuan upah pada daerah penelitian

4. Pedoman analisa SNI No. 28/PRT/2016

5. Rencana anggaran biaya penawaran

Data Primer yang didapatkan adalah:

1. Volume pasangan dinding

2. Analisa Harga Satuan

3. Rancangan Anggaran Biaya pasangan dinding

4. Perbandingan harga anggaran biaya pasangan dinding

Data sekunder yang digunakan dalam penelitian ini adalah data yang di dapatkan dari Pemerintah Kabupaten Klaten selaku pemilik proyek, CV Budi Karya Utama selaku Kontraktor proyek. Sebelum didapatkan kesimpulan maka dilakukan pengolahan data dan pembahasan terlebih dahulu. Tahapan-tahapan pelaksanaan penelitian ini sebagai berikut:

1. Studi pustaka dari berbagi buku-buku literatur dan internet

2. Merangkum teori yang saling berhubungan dengan rencana anggaran biaya dan hal-hal yang terkait 
Jurnal Qua Teknika, Vol. 9 No. 1 Maret 2019

ISSN 2088-2424 (cetak); ISSN 2527-3892 (elektronik)

Fakultas Teknik Universitas Islam Balitar, Blitar

Https://ejournal.unisbablitar.ac.id/index.php/qua; Email: quateknika@unisbablitar.ac.id

Sely Novita Sari. 2019. Evaluasi Anggaran Biaya menggunakan Batu Bata Merah dan Batu Bata Ringan Gedung Kantor Kelurahan Bareng Kecamatan Klaten Tengah Kabupaten Klaten.

Jurnal Qua Teknika, (2019), 9(1) : 1-10

3. Mengumpulkan data dan penjelasan dari sumber yang terpercaya

4. Mengumpulkan data yang didapat dari buku pedoman analisa daerah prambanan 2017

5. Mengumpulkan daftar harga satuan bahan dan upah daerah prambanan 2017

6. Menghitung Analisa Harga Satuan Pekerjaan dinding bata merah dan dinding bata ringan

7. Menghitung rencana anggaran biaya dan kebutuhan masing-masing bahan antara bata merah dengan bata ringan.

8. Membandingkan selisih harga antara bata merah dengan bata ringan.

9. Menghitung kebutuhan bahan pembangunan dinding bata merah dengan dinding bata ringan

\section{HASIL DAN PEMBAHASAN}

Perhitungan volume masing-masing pekerjaan disesuaikan dengan gambar kerja yang telah ditentukan agar didapatkan hasil yang mendekati kenyataan. Untuk bangunan bertingkat perhitungan volume pekerjaan tiap lantai dihitung secara terpisah sesuai dengan dimensi dan spesifikasi yang telah ditentukan. Volume yang dihitung seperti yang terlihat pada gambar 3 dan gambar 4 berikut ini.
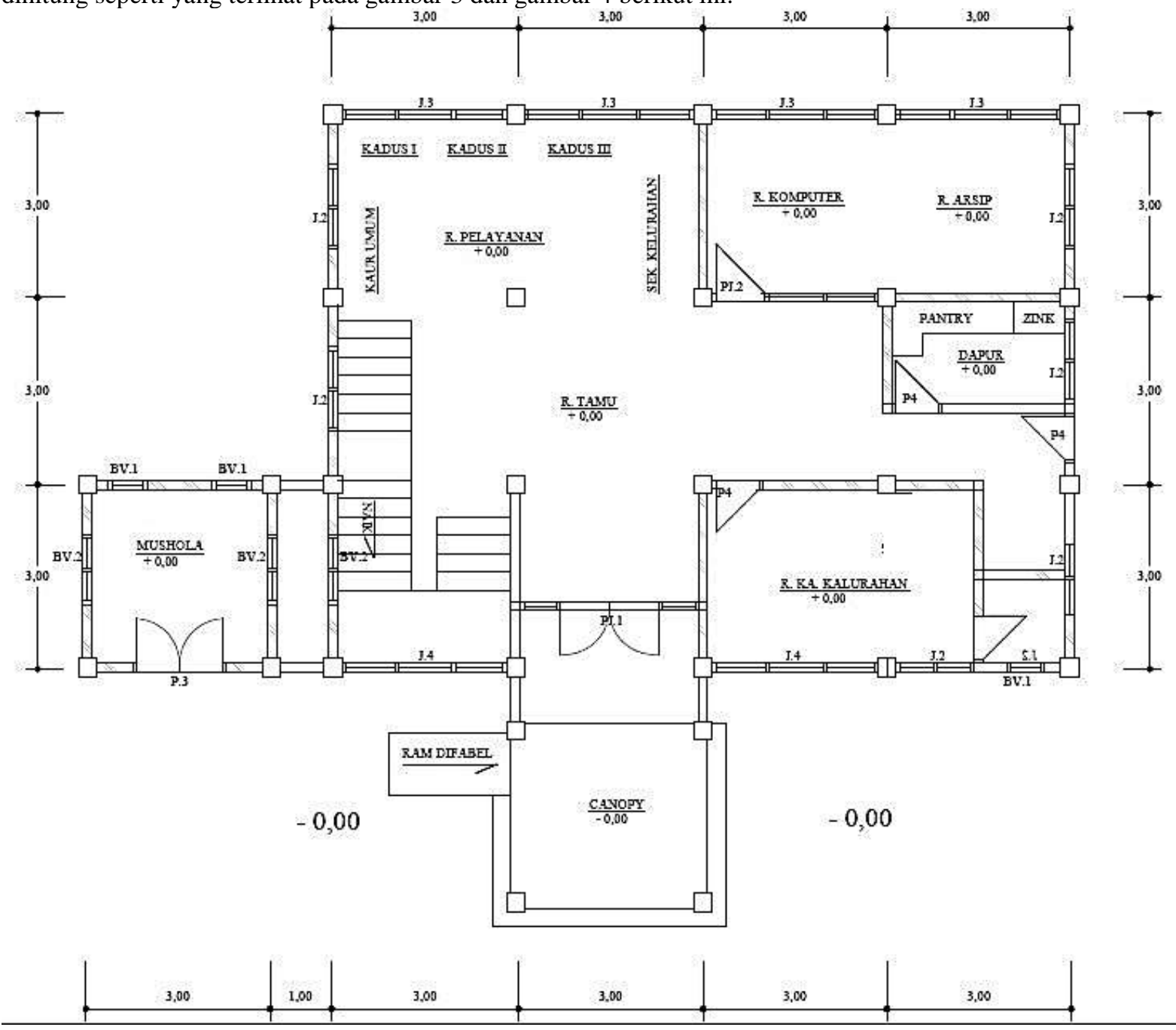

Gambar 3. Denah lantai 1 untuk menghitung volume 
Jurnal Qua Teknika, Vol. 9 No. 1 Maret 2019

ISSN 2088-2424 (cetak); ISSN 2527-3892 (elektronik)

Fakultas Teknik Universitas Islam Balitar, Blitar

Https://ejournal.unisbablitar.ac.id/index.php/qua; Email: quateknika@unisbablitar.ac.id

Sely Novita Sari. 2019. Evaluasi Anggaran Biaya menggunakan Batu Bata Merah dan Batu Bata Ringan Gedung Kantor Kelurahan Bareng Kecamatan Klaten Tengah Kabupaten Klaten. Jurnal Qua Teknika, (2019), 9(1) : 1-10

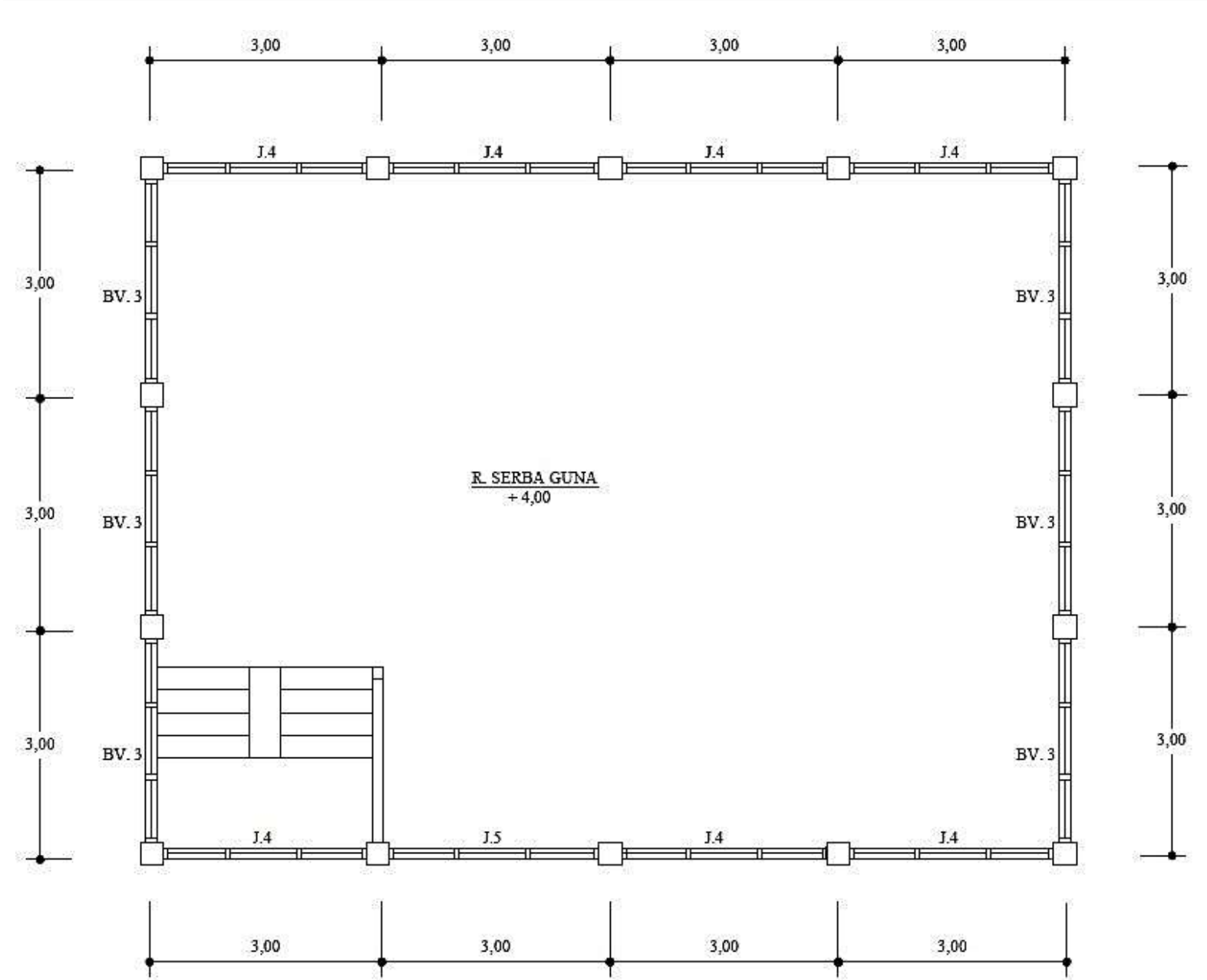

Gambar4. Denah lantai 2 untuk menghitung volume

Volume pasangan dinding yang didapatkan dari gambar asbuild drawing dan shop drawing dimana yang dihitung luasan dinding keseluruhan menggunakan rumus sederhana panjang dikali lebar dan dikurangi komponen-komponen pengurang di dinding seperti kolom, balok, sloof, pintu, jendela dll. Hasil perhitungan volume tersebut adalah $378,63 \mathrm{~m} 2$

Harga satuan bahan sangat perlu diketahui. Hal ini digunakan sebagai acuan penaksiran harga bangunan seluruhnya. Harga bahan didapat dari hasil survei di pasaran yang kemudian dikumpulkan dalam satu daftar yang dinamakan daftar harga satuan bahan. Harga bahan yang dipakai adalah tahun 2018 di Kabupaten Klaten, sesuai dengan lokasi proyek.

Harga satuan pekerjaan adalah jumlah harga bahan dan upah tenaga kerja berdasarkan perhitungan analisis. Analisa harga satuan pekerjaan ini menggunakan SNI 2016. Hasil perhitungan analisa harga satuannya didapatkan bahwa analisa harga satuan untuk pemasangan $1 \mathrm{~m} 2$ dinding bata merah $(5 \times 11 \times 22) \mathrm{cm}$ tebal $1 / 2$ bata campuran 1SP:4PP adalah Rp. 116.545,00 dan analisa harga satuan pemasangan $1 \mathrm{~m} 2$ dinding bata ringan tebal 7,5 cm dengan mortar siap pakai adalah Rp. 225.271,54.

Analisa harga satuan didapatkan dari SNI di masukkan harga sesuai dengan harga bahan dan tenaga ketentuan PU didaerah prambanan, sehingga untuk rancangan anggaran biaya didapat dari harga analisa harga satuan dikalikan dengan volume pasangan dinding. perhitungan banyaknya biaya yang diperlukan untuk bahan dan upah, serta biaya-biaya lain yang berhubungan dengan pelaksanaan bangunan atau proyek tersebut.

\section{$\mathrm{RAB}=\boldsymbol{\Sigma}$ (Volume) $\mathbf{x}$ Harga Satuan Pekerjaan}

Rancangan anggaran biaya pemasangan dinding bata merah merah $(5 \times 11 \times 22) \mathrm{cm}$ tebal $1 / 2$ bata campuran 1SP:4PP adalah Rp. 44.128.086,00 dan rancangan anggaran biaya dinding bata ringan tebal 7,5 $\mathrm{cm}$ dengan 
Jurnal Qua Teknika, Vol. 9 No. 1 Maret 2019

ISSN 2088-2424 (cetak); ISSN 2527-3892 (elektronik)

Fakultas Teknik Universitas Islam Balitar, Blitar

Https://ejournal.unisbablitar.ac.id/index.php/qua; Email: quateknika@unisbablitar.ac.id

Sely Novita Sari. 2019. Evaluasi Anggaran Biaya menggunakan Batu Bata Merah dan Batu Bata Ringan Gedung Kantor Kelurahan Bareng Kecamatan Klaten Tengah Kabupaten Klaten.

Jurnal Qua Teknika, (2019), 9(1) : 1-10

mortar siap pakai adalah Rp. 85.295.824,00. Setelah didapat rancangan anggaran biaya keduanya maka dihitung selisih antara pemasangan dinding bata merah dan bata ringan adalah Rp. 41.167.738,71 sehingga saat kita ambil prosentasinya perbandingannya adalah $48,3 \%$ lebih mahal bata ringan dibandingkan dengan bata merah.

Tabel 3. AHS $1 \mathrm{~m} 2$ dinding bata merah $(5 \times 11 \times 22) \mathrm{cm}$ tebal $1 \frac{1}{2}$ batu campuan $1 \mathrm{SP}: 4 \mathrm{PP}$

\begin{tabular}{|c|c|c|c|c|c|c|}
\hline No & Uraian & Kode & Satuan & Koefisien & $\begin{array}{l}\text { Harga Satuan } \\
\text { (Rp) }\end{array}$ & $\begin{array}{l}\text { Harga Jumlah } \\
\text { (Rp) }\end{array}$ \\
\hline \multirow[t]{6}{*}{ A } & TENAGA & & & & & \\
\hline & Pekerja & L.01 & $\mathrm{OH}$ & 0.300 & $60,000.00$ & $18,000.00$ \\
\hline & Tukang, Batu & L.02 & $\mathrm{OH}$ & 0.100 & $70,000.00$ & $7,000,00$ \\
\hline & Kepala Tukang & L.03 & $\mathrm{OH}$ & 0.010 & $75,000.00$ & 750.00 \\
\hline & Mandor & L. 04 & $\mathrm{OH}$ & 0.015 & $75,000.00$ & $1,125.00$ \\
\hline & & & & \multicolumn{2}{|c|}{ JUMLAH TENAGA KERJA } & $26,875.00$ \\
\hline \multirow[t]{5}{*}{ B } & BAHAN & & & & & \\
\hline & Bata Merah & & buah & 70.000 & $1,000.00$ & $70,000.00$ \\
\hline & Semen Portland & & $\mathrm{Kg}$ & 11.500 & $1,000.00$ & $11,500.00$ \\
\hline & Pasir Pasang & & $m^{3}$ & 0.043 & $190,000.00$ & $8,170,00$ \\
\hline & & & & \multicolumn{2}{|c|}{ JUMLAH HARGA BAHAN } & $89,670.00$ \\
\hline \multirow[t]{3}{*}{ C } & PERALATAN & & & & & \\
\hline & & & & & & \\
\hline & & & & \multicolumn{2}{|c|}{ JUMLAH HARGA ALAT } & \\
\hline $\mathrm{D}$ & \multicolumn{3}{|c|}{ Harga Satuan Pekerjaan $(A+B+C)$} & & & $116,545.00$ \\
\hline
\end{tabular}

Tabel 4. AHS $1 \mathrm{~m} 2$ dinding bata ringan tebal 7,5 $\mathrm{cm}$ dengan mortar siap pakai

\begin{tabular}{|c|c|c|c|c|c|c|}
\hline No & Uraian & Kode & Satuan & Koefisien & $\begin{array}{c}\text { Harga Satuan } \\
\text { (Rp) }\end{array}$ & $\begin{array}{c}\text { Harga Jumlah } \\
\text { (Rp) }\end{array}$ \\
\hline \multirow[t]{6}{*}{ A } & TENAGA & & & & & \\
\hline & Pekerja & L.01 & $\mathrm{OH}$ & 0.670 & $60,000.00$ & $40,200.000$ \\
\hline & Tukang Batu & L.02 & $\mathrm{OH}$ & 1.300 & $70,000,00$ & $91,000.000$ \\
\hline & Kepala Tukang & L.03 & $\mathrm{OH}$ & 0.130 & $75,000,00$ & $9,750.000$ \\
\hline & Mandor & L.04 & $\mathrm{OH}$ & 0.003 & $75,000,00$ & 225.000 \\
\hline & & & & \multicolumn{2}{|c|}{ JUMLAH TENAGA KERJA } & $141,175.000$ \\
\hline \multirow[t]{4}{*}{ B } & BAHAN & & & & & \\
\hline & Bata Ringan tebal $7,5 \mathrm{~cm}$ & & $\mathrm{~m}^{3}$ & 8.400 & 9000 & $75,600.000$ \\
\hline & Mortar siap pakai & & $\mathrm{Kg}$ & 0.473 & 1800 & 851.400 \\
\hline & & & & \multicolumn{2}{|c|}{ JUMLAH HARGA BAHAN } & $76,451.400$ \\
\hline \multirow[t]{3}{*}{ C } & PERALATAN & & $\%$ & 10 & & $7,645.14$ \\
\hline & & & & \multirow{2}{*}{\multicolumn{2}{|c|}{ JUMLAH HARGA ALAT }} & \\
\hline & & & & & & $7,645.14$ \\
\hline D & \multicolumn{2}{|c|}{ Harga Satuan Pekerjaan $(A+B+C)$} & & & & $225,271.540$ \\
\hline
\end{tabular}

Tabel 5. Rancangan Anggaran Biaya Pemasangan Dinding Bata Merah dan Bata Ringan

\begin{tabular}{|c|l|c|c|c|c|}
\hline No & \multicolumn{1}{|c|}{ Uraian Pekerjaan } & Volume & Sat & $\begin{array}{c}\text { Harga Satuan } \\
\text { (Rp) }\end{array}$ & Jumlah \\
\hline & \multicolumn{1}{|c|}{ PEKERJAAN PASANGAN } & & & & \\
\hline 1 & $\begin{array}{l}\text { Pekerjaan pemasangan dinding bata merah } \\
(5 \times 11 \times 22) \mathrm{cm} \text { tebal 1/2 batu campuran 1SP : 4PP }\end{array}$ & 378.6356 & $\mathrm{~m} 2$ & $116,545.00$ & $44,128,086.00$ \\
\hline 2 & $\begin{array}{l}\text { Pekerjaan pemasangan dinding bata ringan tebal 7,5 } \\
\text { cm dengan mortar siap pakai }\end{array}$ & 378.6356 & $\mathrm{~m} 2$ & $225,271.54$ & $85,295,824.71$ \\
\hline & & & & & \\
\hline & & & & selisih & $41,167,738.71$ \\
\hline
\end{tabular}


Jurnal Qua Teknika, Vol. 9 No. 1 Maret 2019

ISSN 2088-2424 (cetak); ISSN 2527-3892 (elektronik)

Fakultas Teknik Universitas Islam Balitar, Blitar

Https://ejournal.unisbablitar.ac.id/index.php/qua; Email: quateknika@unisbablitar.ac.id

Sely Novita Sari. 2019. Evaluasi Anggaran Biaya menggunakan Batu Bata Merah dan Batu Bata Ringan Gedung Kantor Kelurahan Bareng Kecamatan Klaten Tengah Kabupaten Klaten.

Jurnal Qua Teknika, (2019), 9(1) : 1-10

\section{SIMPULAN}

Berdasarkan hasil dari penelitian ini, maka dapat ditarik kesimpulan sebagai berikut :

1. Harga pemasangan pasangan dinding bata merah kantor kelurahan Bareng, kecamatan Klaten Tengah, kabupaten Klaten adalah Rp. 44.128.086,00

2. Harga pemasangan pasangan dinding bata ringan kantor kelurahan Bareng, kecamatan Klaten Tengah, kabupaten Klaten adalah Rp. 85.295.824,71

3. Selisih dari pemasangan pasangan dinding bata merah dan bata ringan adalah Rp. 41.167.738,71

4. Prosentase selisih pemasangan pasangan dinding bata merah dan bata ringan adalah $48,3 \%$

Terkait dengan penelitian ini, disarankan perlunya dilakukan penelitian lanjutan dengan memperhitungkan produktivitas tenaga untuk membandingkan produktivitas tenaga yang dibutuhkan dan melakukan penelitian perhitungan time schedule (kebutuhan waktu) untuk membandingkan time schedule (kebutuhan waktu) dalam pelaksanaan pemasangan dinding.

\section{DAFTAR PUSTAKA}

Anonim. 2016. SNI Nomor 28/PRT/M/2016. Analisis Harga Satuan Pekerjaan Bidang Pekerjaan Umum. Menteri Pekerjaan Umum dan Perumahan Rakyat. Jakarta.

A. G. Tamrin. 2008. Teknik Konstruksi Bangunan Gedung Sederhana Jilid 2. Jakarta: Direktorat Pembinaan Sekolah Menengah Kejuruan, Direktorat Jendral Manajemen Pendidikan Dasar dan Menengah, Departemen Pendidikan Nasional.

A.Z, Zainal. 2005. Analisa Bangunan Menghitung Anggaran Biaya Bangunan. Jakarta: PT. Gramedia Pustaka Utama

Djojowirono, Soegeng. 1991. Manajemen Konstruksi. Yogyakatra: Biro Penerbit KMTS FT UGM

Ervianto, Wulfram I. 2007. Cara Tepat Menghitung Biaya Bangunan. Yogyakarta: CV. Andi Offset.

Frick, Heinz. 1980. Ilmu Konstruksi Bangunan II. Yogyakarta: Kanisius

Frick, Heinz. 1990. Ilmu Konstruksi Bangunan jilid 2. Yogyakarta: Kanisius

Ibrahim, H.Bachtiar. 1993. Rencana Dan Estimate Real Of Cost. Cetakan ke-2. Jakarta : Bumi Aksara.

Ibrahim, H. Bachtiar. 2001. Rencana dan Estimate Real of Cost. Jakarta: Bumi Aksara.

Mukomoko, J. A. 1985. Dasar Penyusunan Anggaran Biaya Bangunan. Jakarta: Gaya Media Pratama.

Niron, John W. 1992. Pedoman Praktis Anggaran dan Borongan Rencana Anggaran Biaya Bangunan. Jakarta: CV. Asona.

Sastraatmadja, A. Soedradjat. 1984. Analisa (cara modern) Anggaran Biaya Pelaksanaan. Bandung: Nova Susanta, Gatut. Panduan Lengkap Membangun Rumah. Jakarta : Griya Kreasi, 2007.

Yayasan Dana Normalisasi Indonesia, (1978), Bata Merah sebagai Bahan Bangunan edisi ke-2, Bandung YDNI, NI-10. 